\title{
ANALISIS PENGIKATAN KONTAINER DI KM. MERATUS SEMARANG
}

\author{
Andi Muhammad Idnan ${ }^{1)}$ Tri Iriani ${ }^{2)}$ Ahmad Fauzi ${ }^{3)}$ \\ Politeknik Ilmu Pelayaran Makassar \\ Jalan Tentara Pelajar No. 173 Makassar, Kode pos. \\ 90172 Telp. (0411) 3616975; Fax (0411) 3628732 \\ E-mail: pipmks@pipmakassar.com
}

\begin{abstract}
ABSTRAK
Kontainer adalah salah satu temuan penting dalam dunia pelayaran yang dapat mempercepat proses pemuatan barang dan transfer dari satu tempat ketempat lain. Pengikatan muatan yang benar akan mengikat muatan sehingga tidak bergeser dari tempatnya selama dalam pelayaran meskipun kapal diterjang badai. Penelitian ini mengalisa penggunaan alat pengikatan kontainer di kapal. Tujuan penelitian ini adalah untuk menganalisa bagaimana penggunaan alat pengikatan kontainer yang dilaksanakan oleh awak kapal di KM. Meratus Semarang. Penelitian ini dilaksanakan di KM. Meratus Semarang. Sumber data yang diperoleh adalah data primer yang diperoleh langsung dari tempat penelitian dengan cara melakukan pengamatan. Penenelitian ini menggunakan deskriptif. Penelitian ini membuktikan bahwa pelaksanaan pengikatan kontainer di kapal belum dilaksanakan sesuai ketentuan sehingga berpotensi pada kecelakaan. Penyebabnya adalah kurangnya pemahaman awak kapal dalam pengikatan kontainer, kurangnya pengawasan dari perwira bagian dek pada saat pengikatan dan terbatasnya peralatan pengikatan diatas kapal.
\end{abstract}

Kata Kunci: Kontainer, lashing.

\section{PENDAHULUAN}

Indonesia adalah negara yang ikut dalam pola angkutan dunia menggunakan petikemas sebagai bagian dari perkembangan teknologi agar terwujud pengangkutan yang efesien dan optimal. Petikemas secara umum dapat digambarkan sebagai gudang yang dapat dipindahkan sekaligus digunakan untuk mengangkut barang. Petikemas merupakan perangkat perdagangan dan sekaligus merupakan komponen dari sistem pengangkutan. Komoditas yang diperdagangkan dalam perdagangan dunia jenisnya beraneka ragam, demikian juga daerah atau negara tujuan 
pengangkutan, maka jenis petikemas yang diperlukan untuk pengangkutan barang berbeda-beda pula.

Untuk menjamin agar petikemas yang diangkut oleh kapal dari satu pelabuhan ke pelabuhan lain maka petikemas tersebut harus diikat. Pengikatan adalah suatu kegiatan mengikat kontainer dengan teknik dan alat tertentu agar petikemas tersebut aman sampai di tempat tujuan. Pelashing perlu juga memperhatikan penempatan muatan yang akan dimuat di atas kapal atau stowage plan agar muatan dijamin aman terhadap risiko pelayaran pada saat kapal dilayarkan. Penyusunan kontainer di kapal terbagi atas dua yaitu di dalam palka (inhold) dan di atas palka (ondeck). Petikemas yang diletakkan dalam palka sudah pasti aman dari pengaruh luar, sedangkan muatan diatas palka harus diberi penguat atau pengikat agar tahan terhadap pengaruh dari luar seperti angin, gelombang serta badai yang mungkin terjadi pada saat pelayaran kapal.

Dalam Cargo Stowage and Securing (CSS) Annex 14 tentang pedoman penanganan dan pengamanan muatan petikemas diketahui bahwa pada saat berlayar, kontainer dapat bergerak ketika mendapat pengaruh dari luar. Dengan demikian penataan muatan selama proses pemuatan di pelabuhan dan teknik lashing muatan yang sesuai dengan standar lashing muatan sangat diperlukan karena dapat berpengaruh terhadap keselamatan kru, kapal dan muatannya selama pelayaran.

Setiap proses pengikatan seharusnya dapat memenuhi ketentuan cara ikat kontainer yang benar. Meskipun teknik standar pengikatan petikemas yag aman telah ditetapkan tetapi dalam kenyataannya masih terjadi kesalahan yang dapat berakibat fatal seperti yang dialami oleh KM. Meratus Semarang yang berlayar dari Tanjung Priok menuju Timika pada tanggal 17 April 2018. Ketika KM. Meratus Semarang berada di Laut Banda, terjadi rolling pada KM. Meratus Semarang setinggi \pm 5 . Derajat. Rolling pada KM. Meratus Semarang mengakibatkan sebuah kontainer yang berada pada bay 17 row 5 dan tier 3 bergeser dan hampir jatuh ke 
laut yang disebabkan oleh renggangnya alat pengikat berupa bridge fitting dan pengikat bar. Hal ini terjadi karena pada saat pemuatan di pelabuhan Tanjung Priok, awak kapal hanya menggunakan 2 buah base cone/twistlock, padahal seharusnya menggunakan 4 buah twistlock. Teknik pengikatan yang salah ini menjadi penyebab bergesernya petikemas di KM. Meratus Semarang pada saat rolling. Pengikatan muatan yang benar akan membuat petikemas tidak bergeser dari tempatnya selama pelayaran meskipun terjadi badai dalampelayaran. Muatan yang bergeser tersebut dapat berakibat buruk pada stabilitas kapal yang dapat mengakibatkan kerugian bagi pihak kapal dan pemilik muatan.

Berdasarkan latar belakang diatas, maka rumusan masalah dalam penelitian ini adalah bagaimana penggunaan alat pengikatan kontainer di kapal KM. Meratus Semarang?

Tujuan penelitian ini adalah menganalisa bagaimana penggunaan alat pengikatan kontainer yang dilaksanakan oleh awak kapal di KM. Meratus Semarang.

\section{TINJAUAN PUSTAKA}

\section{A. Kontainer}

Kontainer (peti kemas) adalah satu kemasan yang dirancang secara khusus dengan ukuran tertentu, dapat dipakai berulang kali, dipergunakan untuk menyimpan dan sekaligus mengangkut muatan yang ada di dalamnya. Biasanya muatan yang dimasukkan dalam kontainer adalah muatan yang mudah rusak atau muatan yang memerlukan penanganan dan perawatan yang lebih dari muatan biasanya, dengan menggunakan kontainer kerusakan dari muatan dapat dicegah atau dapat diminimalisir sehingga kerugian yang timbul dapat dikurangi. Adapun keuntungan secara ekonomis pada kontainer adalah :

1. Muat dan bongkar dapat dilakukan dengan cepat dan aman.

2. Buruh yang digunakan tidak terlalu banyak yang berarti 
penghematan terhadap biaya stevedore.

3. Kerusakan dapat ditekan sekecil mungkin.

4. Biaya keseluruhannya menjadi murah.

Menurut Tumbel (1991) penggunaan sistem kontainer maka keuntungan - keuntungan yang dapat dicapai adalah sebagai berikut:

1. Waktu yang digunakan pada saat muat bongkar lebih efisien.

2. Memudahkan pengawasan oleh pihak, karena pemuatan bisa dilaksanakan digudangnya sendiri serta mengurangi resiko kerusakan dan pencurian.

Kontainer memiliki 3 jenis ukuran yaitu kontainer 20 kaki, 40 kaki dan 45 kaki yang masing - masing mempunyai berat dan ukuran yang berbeda. Berat maksimum peti kemas muatan kering 20 kaki adalah $24.000 \mathrm{~kg}$, untuk 40 dan 45 kaki (termasuk high cube container), adalah $30.480 \mathrm{~kg}$. Sehingga berat muatan bersih/payload yang bisa diangkut adalah $21.800 \mathrm{~kg}$ untuk $20 \mathrm{kaki}, 26.680 \mathrm{~kg}$ untuk $40 \mathrm{kaki}$, dan 25.680 untuk kontainer 45 kaki.

\section{B. Pengikatan}

Pengikatan adalah suatu pengawasan pengamanan atas pengikatan cargo atau muatan untuk proses transportasi sehingga aman sampai ditempat tujuan. Pengikatan muatan atau pengamanan pengikatan muatan cargo baik melalui transportasi darat, transportasi laut maupun udara. Walaupun dengan adanya lashing perlu juga diperhatikan pengaturan penempatan muatan yang akan dimuat di atas kapal atau stowage plan agar muatan betul - betul aman pada saat melakukan pelayaran. (Egbert Edward : 2006)

Pada kegiatan pengikatan pastikan sebelum muatan akan diikat, alat dan kelengkapan lashing seperti lashing bar, turnbuckle, wire, bridge fitting maupun peralatan pengikatan lainnya telah cukup dan tersedia. Karena jika kurang dan proses ikat sudah dimulai, akan memakan waktu untuk 
mencari penambahannya, terkhusus jika muatan yang diikat diatas kapal dimana waktu dan tenaga dari kru kapal harus diperhitungkan. Memastikan prosedur pelashingan sesuai, kemampuan atau bobot peralatan sesuai dan mampu menahan beban muatan yang diikat, jumlah titik ikat cukup disesuaikan dengan berat muatan, dan memastikan alat ikat yang digunakan sesuai dan aman bagi muatan itu sendiri.

Tujuan pengikatan kontainer adalah untuk mencegah muatan agar tidak bergerak atau tidak keluar dari kedudukannya pada waktu kapal mengoleng mengangguk atau merewang ketika kapal mengalami cuaca buruk. Apabila muatan kontainer tidak diikat, itu akan berpengaruh terhadap stabilitas kapal yang mengakibatkan kapal akan miring ataupun terbalik akibat dari muatan yang bergerak, dan dapat merugikan perusahaan akibat muatan yang jatuh kelaut pada saat pelayaran.

\section{METODE PENELITIAN}

Berdasarkan data yang telah dikumpulkan, maka dalam menganalisis data penulis menggunakan metode deskriptif yaitu paparan dan uraian yang didapatkan dari studi kepustakaan dan hasil dari pengamatan mengenai suatu permasalahan analisis metode pelashingan muatan diatas kapal berdasarkan data yang menjelaskan tentang hasil observasi, dan studi pustaka.

Selanjutnya data-data yang telah diperoleh dari langkah-langkah tersebut, maka kita dapat mengumpulkan data yang berkaitan dengan objek penelitian sehingga dapat disimpulkan secara tepat sesuai dengan rumusan masalah. Kemudian kita memberikan saran yang sesuai dengan apa yang disimpulkan dan dapat merupakan bahan masukan dalam mengatasi masalah tersebut, barulah langkah-langkah ini dianggap selesai. 


\section{HASIL PENELITIAN DAN PEMBAHASAN}

A. Hasil Penelitian

Hasil penelitian menjelaskan mengenai hasil-hasil penelitian dan fakta-fakta yang didapatkan pada saat melaksanakan praktek laut di kapal KM. Meratus Semarang. Penulis melaksanakan praktek laut selama 1 tahun 6 hari. Selama penulis melaksanakan praktek laut ada beberapa kejadian - kejadian yang penulis temukan pada saat pelashingan kontainer, diantaranya :

1. Ketika KM. Meratus Semarang berada dipelabuhan Amamapare, Timika dan akan berangkat ke Jakarta, pada saat proses pengikatan kontainer dilakukan oleh crew kapal yaitu Bosun, 3 AB dan 2 Cadet Deck. Pada saat pemuatan kontainer sedang berlangsung diatas deck, Mualim 1 memerintahkan seorang cadet untuk mengganti beberapa twistlock yang berada di standchain karena sudah rusak dan tidak layak untuk digunakan.

2. Perjalanan KM. Meratus Semarang dari Tanjung Priok, Jakarta ke Amamapare, pada tanggal 17 April 2018 tepat berada di Laut Banda, kapal mengalami olengan $\pm 5^{\circ}$ karena pengaruh dari cuaca yang kurang baik, yang mengakibatkan sebuah kontainer yang berada pada bay 17 row 5 dan tier 2 bergerak dan hampir jatuh kelaut disebabkan alat lashing berupa bridge fitting dan lashing bar terlepas maupun renggang.

3. Pada saat melakukan kegiatan bongkar muat dipelabuhan Amamapare, pengikatan kontainer dilakukan oleh Bosun, 3 AB dan 2 Cadet deck. Sebelum kapal berangkat tujuan Kalabahi, Maulim 1 melaksanakan pemeriksaan kembali ikatan-ikatan kontainer, dan didapatkan pada bay 9 dan centre tidak terpasang bridge fitting di atas kontainer, begitu juga pada bay 19 masih terdapat lashing bar yang masih renggang atau tidak dikencangkan.

4. Kapal pada saat melaksanakan kegiatan pemuatan di pelabuhan Tanjung Priok, pemasangan base cone/twistlock yang seharusnya 
menggunakan 4 buah twistlock tapi pada kenyataanya hanya menggunakan 2 saja dan mengakibatkan kontainer bergerak pada saat berlayar menghadapi cuaca buruk.

\section{B. Pembahasan}

Pada intinya dalam pemuatan di atas dek kapal menyangkut beberapa aspek, antara lain prinsip memuat dan cara pemuatan dan yang paling penting adalah pengawasan kru dalam menjalankan pengikatan. Sesuai dengan fakta yang ada, sumber-sumber kerusakan terhadap muatan didalam kontainer terjadi pada saat pelayaran. Pada tanggal 17 Maret 2018 pelayaran dari Jakarta tujuan Amamapare, pada saat itu terjadi cuaca yang buruk di laut Banda dan kapal mengalami olengan yang cukup besar yang mengakibatkan kontainer diatas deck lebih tepatnya pada bay 17 row 5 dan tier 3 bergerak dan hampir jatuh kelaut dikarenakan alat lashing berupa bridge fitting lepas dan jatuh kelaut dan lashing bar renggang yang mengakibatkan kontainer bergerak karena pengaruh yang timbul dari luar.

Oleh karena itu untuk menghindari hal-hal yang tidak diinginkan terhadap muatan kontainer pada saat dalam pelayaran, maka perlu adanya pengamanan dengan cara melashing kontainer dan pengawasan yang harus dilakukan perwira dek pada saat kapal akan berangkat untuk menghindari hal yang tidak diingkan pada saat dalam pelayaran. Seperti hasil penelitian yang dilakukan pada waktu melaksanakan praktek laut diatas kapal KM. MERATUS SEMARANG tujuan dari teknik pengamanan kontainer belum sepenuhnya tercapai yang semuanya disebabkan oleh tidak optimalnya pengamanan muatan kontainer diatas kapal maupun kurangnya pemahaman kru dek kapal atas prosedur lashing muatan on deck yang benar.

Maka berdasarkan analisa diatas, dapat dinyatakan bahwa optimalisasi pelaksanaan pelashingan muatan on deck KM. MERATUS SEMARANG belum memenuhi standard lashing terbukti kebenarannya. Dikarenakan pengawasan saat pelaksanaan pelashingan dikapal tidak 
pernah dilakukan yang mengakibatkan pelashingan kontainer tidak terlaksana sesuai dengan prosedur dan mengakibatkan muatan dapat bergerak akibat dari alat lashing yang kendor.

Susunan Kontainer yang berada pada tier 84 tidak terpasang bridge fitting dan pada tier 82 dan 84 tidak terdapat atau tidak digunakan lashing bar yang disilang sesuai prosedur untuk menghubungkan dengan kontainer yang diatas. Dan juga kurangnya peralatan pelashingan membuat pelaksanaan lashing tidak berjalan sesuai dengan prosedur. Sehingga hal inilah yang mengakibatkan lashing tidak sempurna atau tidak optimal atau pergeseran pada kontainer.

Pengawasan terhadap proses lashing kontainer oleh perwira dikapal. Pengawasan terhadap crew yang melaksanakan pengikatan kontainer sangatlah penting. Sebab dengan pelashingan yang baik kapal dan muatan yang dibawanya akan selamat sampai pelabuhan sesuai dengan tujuan sebuah pelayaran. Pelashingan kontainer yang tidak sesuai prosedur dapat diketahui dengan pengamatan secara langsung pada saat kontainer yang telah dimuat dan dalam proses pelashingan. Maka akan diketahui ketidak telitian crew pada saat melakukan pelashingan kontainer sebagai contoh berikut :

a. Peralatan pelashingan yang tidak dirawat secara rutin yang mengakibatkan banyak peralatan lashing yang rusak dan tidak laik untuk digunakan.

b. Perwira jaga tidak pernah melakukan pengecekkan pelashingan kontainer yang mengakibatkan terdapat beberapa kontainer yang alat lashingannya kendor.

Untuk menghindari hal - hal tersebut di atas sangat perlu untuk diperhatikan proses pengikatan kontainer yang dilakukan oleh crew, sehingga apabila terjadi proses pelashingan kontainer yang tidak sesuai atau sebagaimana mestinya maka perwira kapal yang berjaga dipelabuhan bisa mengingatkan secara langsung untuk segera 
dibenahi. Menurut penulis dengan pengawasan secara langsung tidaklah cukup akan tetapi apabila proses pemuatan kontainer diatas kapal telah selesai ada baiknya perwira kapal memeriksa kembali hasil lashingan kontainer tersebut untuk menyakinkan bahwa semua alat alat lashing telah terpasang dengan sebagaimana mestinya, atau benar dan semua alat lashing telah terkunci dan kencang semuanya.

Setelah diyakini alat lashing kontainer telah terpasang sempurna ada baiknya alat lashing yang tidak terpakai lagi dimasukkan ke kotaknya kembali agar tetap dalam keadaan baik. Pengawasan pelashingan bukan hanya pada saat kapal selesai muat dan bongkar, tetapi dilakukan ketika kapal dalam suatu pelayaran. Hal ini dilakukan untuk memastikan peralatan lashing masih dalam keadaan yang aman dan kencang sehingga muatan tidak mudah bergeser dan tetap dalam kedudukannya.

Faktor Yang Mengakibatkan Tidak Maksimalnya Lashing di KM. Meratus Semarang berdasarkan pengamatan yang dilakukan diketahui bahwa yang menyebabkan tidak maksimalnya lashing kontainer adalah: a Kurangnya pengetahuan ataupun kepatuhan diri dari crew diatas kapal dalam melaksanakan pelashingan kontainer dengan baik dan benar sesuai dengan prosedur. Pada proses pelashingan di kapal KM. MERATUS SEMARANG, personil yang bertindak selaku pelaksana lashing kontainer adalah crew kapal bagian dek yang terkadang mengabaikan hal - hal kecil seperti tidak mengunci twistloock dikarenakan kurang paham dan juga masih mengabaikan lashingan yang sudah kendor.

b. Kualitas alat lashing kontainer yang tidak layak untuk dipakai dan masih dipergunakan.

c. Karena terdapatnya alat lashing kontainer yang rusak seperti sebutkan di atas terkadang alat lashing kontainer yang seharusnya sudah tidak layak dipakai sering dipaksakan untuk tetap digunakan, sehingga akan membahayakan muatan kontainer dalam pelayaran. 
d Terbatasnya alat lashing kontainer diatas kapal.

Dikatakan terbatas disebabkan karena kurangnya alat lashing diatas kapal dan jika dalam jumlah banyak muatan akan kekurangan alat lashing sehingga ada sebagian kontainer yang tidak terlashing. Kekurangan alat lashingan ini dapat penulis amati disebabkan karena kecerobohan dan kelalaian dari crew kapal pada saat membuka lashingan. Alat lashingan yang dilepaskan pada saat pembongkaran kontainer dilemparkan dengan sengaja kebawah sehingga ada sebagian yang jatuh ke laut, ada juga yang rusak.

e. Disebabkan karena kurangnya pengawasan dari pihak kapal atau perwira kapal terhadap crew yang melaksanakan pelashingan kontainer, maka crew kapal dapat melakukan pelashingan kontainer sesuai dengan keinginan dan kemampuannya saja. Sehingga masih terdapat pelashingan yang tidak sesuai prosedur bahkan ada yang tidak terpasang dan masih longgar yang dapat membahayakan muatan. Contohnya pada pemasangan twist lock atau pemasangan bridge fitting.

\section{Pemecahan Masalah}

Berdasarkan analisa data yang peroleh saat sedang melaksanakan praktek berlayar di kapal KM. MERATUS SEMARANG, diuraikan solusi sebagai pemecahan masalah yang dianggap baik dalam mengatasi permasalahan yang dihadapi antara lain :

1. Menambah pengetahuan crew bagian dek tentang bagaimana cara lashing kontainer sesuai dengan prosedur.

Dalam hal ini pihak perusahaan bertanggung jawab memfasilitasi pelatihan prosedur kontainer lashing secara berkala dan dalam pelaksanaannya dibentuk sebuah badan sebagai pengawas dan penanggung jawab untuk mendapatkan hasil sesuai dengan tujuan awal yaitu mendapat pengetahuan yang cukup tentang prosedur kontainer lashing dan dapat diterapkan di kapal. 
2. Menambah cadangan alat lashing kontainer.

Cadangan alat ikat kontainer dikapal sangatlah perlu bagi kapalkapal kontainer karena jika mana kapal memuat kontainer dalam jumlah berlebihan maka pengggunaan alat lashing yang dibutuhkan akan berubah sebab akan ada beberapa yang tidak dapat terikat jika alat pengikatan kurang. Terdapatnya cadangan alat lashing di kapal. Kekurangan alat lashing tersebut disebabkan karena :

a. Jatuh ke laut

b. Rusak atau tidak layak pakai

Dengan memperhatikan hal tersebut diatas, cadangan alat lashing kontainer di kapal sangat diperlukan sekali. Karena sewaktu-waktu permintaan alat lashing kontainer dari perusahaan mengalami keterlambatan, maka cadangan alat ikat kontainer yang ada dapat di pakai. Sehingga bila alat lashing kontainer sudah sampai di kapal difungsikan sebagai cadangan atau spare, karena cadangan alat ikat kontainer yang lama telah terpakai. Dengan cara demikian masalah kekurangan alat ikat kontainer tidak akan terjadi lagi dan keselamatan kapal dan muatannya dapat terjaga.

3. Pemeriksaan dan Perawatan alat ikat.

Untuk menjaga kualitas serta kelayakannya sebuah alat ikat kontainer sangatlah penting, karena dengan perawatan yang baik dan terkontrol maka akan menambah umur pemakainya alat lashing tersebut. Adapun cara perawatan alat ikat kontainer tersebut antara lain :

a. Pemberian greace atau gemuk secara berkala terhadap alat ikat kontainer. Pemberian gemuk sangatlah perlu, karena dengan pemberian gemuk atau greace secara berkala akan menghindari :

1) Alat ikat cepat berkarat.

2) Alat ikat yang berulir macet karena berkarat.

b. Memasukkan alat lashing kontainer kedalam kotak-kotak setelah kegiatan bongkar muat. Karena setelah proses pembongkaran akan 
lebih baik apabila semua alat lashing kontainer yang telah dilepas untuk dipindahkan satu dan dipisah-pisahkan menurut fungsinya serta kemudian dimasukkan kedalam kotak yang tersedia diatas kapal. Adapun keuntungan yang diperoleh dengan cara in :

1) Deck kapal akan kelihatan lebih rapi.

2) Jumlah dari alat-alat lashing selalu terkontrol.

3) Menghindari pencurian.

4) Pengawasan terhadap alat pelashingan lebih mudah.

4. Pengawasan terhadap proses lashing kontainer oleh perwira dikapal.

Pengawasan terhadap crew yang melaksanakan pengikatan kontainer sangatlah penting. Sebab dengan pengikatan yang baik kapal dan muatan yang dibawanya akan selamat sampai pelabuhan sesuai dengan tujuan sebuah pelayaran. Pengikatan kontainer yang tidak sesuai prosedur dapat diketahui dengan pengamatan secara langsung pada saat kontainer yang telah dimuat dan dalam proses pengikatan. Maka akan diketahui ketidak telitian crew pada saat melakukan pengikatan kontainer sebagai contoh berikut:

c. Kadang ada sebagian kontainer yang tidak terkunci terutama twist lock.

d. Ada sebagian alat lashing kontainer yang tidak kencang terutama pada pemasangan bridge fitting.

e. Terdapat juga alat lashing kontainer yang tidak terpasang semestinya dan lashing bar yang masih kendor.

Untuk menghindari hal-hal tersebut dianggap sangat perlu untuk diperhatikan dimana proses pengikatan kontainer yang dilakukan oleh crew, sehingga apabila terjadi proses pengikatan kontainer yang tidak sesuai atau sebagaimana mestinya maka perwira kapal yang berjaga di pelabuhan bisa mengingatkan secara langsung untuk segera dibenahi. Pengawasan secara langsung tidaklah cukup akan tetapi apabila proses 
pemuatan kontainer di atas kapal telah selesai ada baiknya perwira kapal memeriksa kembali hasil ikatan kontainer tersebut untuk menyakinkan bahwa semua alat-alat lashing telah terpasang dengan sebagaimana mestinya, atau benar dan semua alat ikat telah terkunci dan kencang semuanya.

Setelah diyakini alat ikat kontainer telah terpasang sempurna ada baiknya alat ikat yang tidak terpakai lagi dimasukkan ke kotaknya kembali aagar tetap dalam keadaan baik.

\section{SIMPULAN DAN SARAN}

A. Simpulan

Ketidakoptimalnya pelaksanaan pelashingan yaitu kurangnya pemahaman kru terhadap pelashingan kontainer sesuai dengan prosedur dan kurangnya pengawasan dari perwira bagian dek terhadap pelaksanaan pelashingan kontainer diatas kapal

B. Saran

Upaya yang dapat direalisasikan dalam pelaksanaan pelashingan kontainer di atas kapal KM. MERATUS SEMARANG yaitu sebaiknya diadakan pelatihan terhadap kru kapal khususnya bagian dek dalam proses pelaksanaan pelashingan yang sesuai dengan prosedur. Setelah diadakan pelatihan maka disarankan ada seseorang yang ditunjuk dari pihak perusahaan atau dari pihak kapal untuk mengontrol dan mengawasi hasil dari pelatihan tersebut agar kedepannya tidak terjadi lagi kesalahan pada saat melaksanakan pelashingan kontainer di atas kapal sehingga dapat berjalan secara baik sesuai dengan prosedur pelashingan. 


\section{DAFTAR PUSTAKA}

[1]. Tumbel, A.H. (1991). Peti Kemas Dan Penanganannya

[2]. Martopo, A. (2001). Penanganan Muatan.

[3]. ARPAL Marine Survey. (2011). Lashing and securing Deck Cargoes Disadur pada 20 Oktober 2020 dari http://www.arpalmarinesurvey.blogspot//Lashingandsecuring//2011

[4]. Edward, E. \& Palembangan, S. (Oktober 2006). Modul Bahan Ajar Penanganan, Pengaturan Dan Pengamanan Muatan: Politeknik IImu Pelayaran Makassar.

[5]. Istopo (1999). Kapal dan Muatannya.

[6]. Knot., J. R. The Nautical Institute Lashing and Securing of Deck Cargoes

[7]. Suzdayan (2012). Container Ship and Cargo Securin. Disadur pada 20 Oktober 2020 dari http://www.scirbd.com/doc/container-shipand-cargo-securing 